INVITED 2012 CARROLL D. Clark LECTURER

AT THE

UNIVERSITY OF KANSAS 



\title{
INTERVIEW WITH MARY C. WATERS
}

\author{
INTERVIEW CONDUCTED BY: \\ DANNY ALVORD \\ University of Kansas \\ KEVIN MCCANNON \\ University of Kansas
}

Dr. Mary C. Waters is an Amy Zuckerman professor of Sociology at Harvard University who specializes in race, ethnicity, and immigration.

ALVORD: Mary Waters, thank you so much for taking the time to be here with us today. We really, really appreciate it.

WATERS: Well I'm very happy to be here.

ALVORD: You have enjoyed quite a distinguished career so far at Harvard and you've really been known so far with your work in race and ethnicity and immigration. Before your lecture yesterday at the Clark lecture you discussed more recent work that you've been doing, you've been involved with - which is taking a somewhat different direction which you acknowledge-I was wondering if you wouldn't mind telling us a little bit about that project and how it fits and departs from your wider research agenda.

WATERS: Most of my work has been on racial and ethnic identity, and immigration and the integration of the children of immigrants into society. And I-I don't really restrict myself to any one area of research but as I was doing work on the children of immigrants, I got invited to be on this McArthur research network on the transition to adulthood. And they were looking at young adults around the country and they wanted someone who knew about the children of immigrants and young adulthood. And so, I spent ten years on this interdisciplinary 
research network thinking about how young adulthood has changed, and one of the ways in which we were thinking about it was about community colleges. And some economists on the panel were doing a study of what keeps people in community colleges, and one of the places where they were doing an experiment (actually, where they were paying people for good grades) was in New Orleans.

And when the hurricane hit, we had a meeting right after that, and they said, 'Oh, well, we're going to have to get rid of our study because of the hurricane we won't be able to follow people.' And I knew that we had health data and all kinds of data on social support, et cetera, so I just said "We should really keep following these people and find out what happened." And while it's taken me into disaster research and health research, and things I hadn't really done before, there's some continuities in that the people we were following were all African-Americans, and they're moving into new neighborhoods with Latinos and whites for the first time so there's the issue of intergroup relations which has been central to my work. And then also they're all young adults - so the question of how they're navigating their adulthood is another continuity. But one of the fun things about being a sociologist is that almost anything is fodder for our interest, and a great thing is that you can just follow your interests and when a research opportunity comes up, you know you're not limited and you can learn about new things, and that's also really exciting. So moving into a new field, you meet new people, you get exposed to new ideas, you learn about things, so this book-continuities and fresh challenges, so I like that.

ALVORD: I wonder: did you face any sort of challenges, and sort of picking up someone else's research project, like kind of midway through?

WATERS: Well, there was a big challenge which is that we had to get human subjects IRB approval to be able to go back to the people who had signed up for a longitudinal study of educational outcomes to change it to be about the impact of hurricane. And I was working with people from Princeton, I was at Harvard, there was also somebody at U-Mass Boston, and at Tulane, and also the 
survey research firm, and the original study was out of MDRCwhich is a research firm that does experimental research, field experiments. So all of those different IRBs had to approve this research. And, the original IRB that had approved it (at MDRC) was very skeptical about whether or not we should be allowed to do this. And the issue was whether it would-whether it was violating the agreement we had given to people at the beginning, and also whether or not it would upset people too much to talk about the hurricane. And we made the argument that people would want to talk about something like this. And there was the ongoing study of the educational outcomes so we wanted to know whether people reenrolled, and so we were going to continue the original thing. We are, actually, one of my graduate students is writing her dissertation on community colleges and how people navigate them. So we are continuing the original part but we made the argument that it would be crazy to call these people and not mention Katrina. They are scattered all over the country, their community college was under water, so they agreed to it, eventually, and people have been very happy to be asked about this. And in fact, they just say, 'You know, we're so glad that we had somebody to talk to about this experience.'

ALVORD: Did you face any unique challenges, or what were sort of the pros and cons or experiences of working on such a large interdisciplinary team?

WATERS: It's been a really interesting experience because we have, we all bring our different perspectives, and also even just vocabulary, so when we had to think, you know, about running analyses on the survey data, the economists would do it one way, the psychologists another, and the sociologists... 'I want to do a multiple regression.' 'No, we should do an ANOVA,' and we would have to argue about what statistical approach was right. And so, it was very interesting because you get to examine your sort of reflex of just... ideas that you don't even think through about why you do things in a particular way. But generally, we've all worked really well together. We have lab meetings where we bring together graduate students from the different projects. My main collaborator Jean Rhodes is at U-Mass Boston, so we're at least in 
the same city. And then we Skype in, or we conference call in, our collaborators - Beth Fussell who is now at Tulane for the year and is usually at Washington State. And then we had a big disruption because the main economist we were working with-Christina Paxson-just got named president of Brown University. So she had to come off the project because she's not going to have time to do that and still be president of a university. We brought on another economist who had started out with us but she had gone to work in The White House for two years in the President's council of economic advisors so Cecelia Rouse came back out of The White House right when Christina was going to Brown. So, we've had comings and goings.

MCCANNON: I wanted to get more from you with thissince the project started really before the hurricane hit, this is sort of an accident that you were able to take advantage of. And thinking about it from that point of view, could you talk a little bit more about what that really meant for the project? To say, 'Hey, wow, this big event just happened.' How do you handle that? What did you and the research team do when that happened? Did you approach it—how did you think about that?

WATERS: Well, the main thing that got us thinking about it was that, we had asked a lot of questions because the original question was whether education-more education-influenced people's mental and physical health. So we had asked all these questions about mental and physical health, and we had asked questions about social support, for trying to understand if people had the social support they needed to finish college. So we had asked all these questions which had incredible meaning for a hurricane. So when we thought about going back, we realized that we could ask the same questions again and get an estimate of the effect of the hurricane net of people's previous beliefs and experiences. And that's very rare in disaster studies. So we knew that we were sitting on data that was very important. And so immediately, we thought about how we would get funding to find these people-and we were really curious as whether or not we would be able to, we really weren't sure because the community college was under water and closed down. Nobody knew where anybody was. But in 
those first few months, the National Science Foundation had money available for studying disaster, and it was a quick turnaround. So if you got an application in fast, you could get some money. So we wrote up an application very quickly, and we got some money also from the McArthur Foundation, that was sponsoring our research network. So between those two we were able to get the survey research firm to immediately start looking for people. And most of the phone numbers didn't work, but we did have their social security number and what we learned was that if you apply for a job, if you apply to rent, or a place to live, you pop into these databases that the survey research firm can find.

So, we also sent people out to-basically once New Orleans started to open back up - to look at houses and see were they under water, were they abandoned, were people still there. We asked neighbors, 'Do you know where the people who used to live here might be?' But people had also given us the phone numbers, you know, as usual in a longitudinal study, we asked 'Is there anybody who would know where you were?' But the problem was of course, was that everybody in New Orleans was displaced. So if you couldn't find this person, you also couldn't find their mother or their sister or their best friend who they had given us the numbers of. Although some of the people had cellphones so we were able to find them, wherever they were.

MCCANNON: Interesting. That actually led me to another question that came about the interdisciplinary research and you mentioned specifically, "okay, now we have this opportunity we really need the funding to do this." Could you tell a little bit about your experience with putting together a grant proposal really almost on the fly, if you will, but within an interdisciplinary [team]. Because it is one thing to be a single P.I., and write a grant proposal. But then to have all these different individuals and especially something that has a real quick deadline. Do you want to talk about that a little bit?

WATERS: Chris Paxson, who was the economist who was at Princeton and is now at Brown was the lead P.I. and she was just amazing and organized all of these different sub-entities. So I had my sub-grant at Harvard, and there was another sub-grant 
at U-Mass, and so we all had to work together to put this together and it was a big logistical issue. Not so much the interdisciplinarity part of it, but just having so many institutions involved. Because they all have, your grants person, and you have to get your budgets, and you all have different rules about how much you pay people, and all those kinds of things.

MCCANNON: Right.

WATERS: So it was a very big undertaking to do that. After NSF and the McArthur Foundation, we applied to the National Institute of Health. So that's where we got the five year funding to do the follow-ups and follow people over time. And that was a huge grant. We're in the last year of that grant so now we're gearing up to reapply for another five years of funding.

ALVORD: One thing that you mentioned at the end of your lecture yesterday was sort of the policy implications for cities, local governments, dealing with disasters. You know you mentioned that climate change disaster is much more likely to occur. So I just wonder if you could talk a little about the policy implications that you would like to see come out of your research.

WATERS: Well, one of them is just the idea that you need to have preparation and thinking about what's going to happen when a disaster hits - which I think is becoming more and more prevalent. It was very clear that New Orleans was completely unprepared for this even though it had been predicted over and over again that this was going to happen. But they were not prepared to evacuate people who didn't have cars. They were not prepared to give the right advice to people.

We found - and actually this has been found in other studies too- that most people who don't evacuate don't do so for selfish reasons, they actually do so for very altruistic reasons. So a lot of the people who didn't evacuate that we interviewed had elderly relatives who they couldn't leave behind, had jobs where they were told by their employers that they should stay. Some of them were maids in downtown hotel rooms - and the usual policy in these hotels was that they would give rooms to employees, so they could 
be there. They would stay on higher floors, and when the hurricane was over they would have the workers that they needed even if there's an evacuation. Well these women who were maids in these hotel rooms stayed there, and then when it flooded, the hotels just put them out. And they ended up at the convention center. They brought their families, because that was also the usual policy to bring your family and stay in the hotel rooms. So there were all kinds of really bad decisions that were made in preparation for the hurricane and then there are things that you can find out by following people over time. One of the most amazing findings that we had was the lasting impact of pet loss. So we added this question at the last minute, you know, many of us have pets, dogs, and cats, and we thought 'Well what do you do about this?' We asked a question whether they lost a pet, whether their pet died. And that was a reason that some people gave for not evacuating, was that they couldn't leave behind their dog or their cat. And it turned out that pet loss-especially for people who had low social support before the hurricane-was a lasting cause of depression and anxiety after the hurricane. So people's psychological health was very much damaged by losing their pet - not only because they lost this source of love and support in their lives, but also because they had incredible guilt because they left their pet behind and the pet died. So I mentioned this because this is kind of a simple issue that policymakers I don't really talked, thought about - which is, people won't evacuate because people want to protect their pet, and shelters don't usually take pets. Or if they do, they tell you that you have to bring your pet's vaccination records which, as I pointed out in the talk, it's not like a lot of people have those at their fingertips when a giant hurricane is coming. So I really think that they need to think about that issue for future evacuations.

MCCANNON: I was curious also about that. Some other past research you'd done was with the U.S. Census with the racial categories and the implications for people who identify as multiracial. And I don't know if you could talk a little bit about that-about what that means for sociologists conducting research, particularly if they are using these various large datasets that have very limited racial categories. You know, 'black, white, Hispanic' 
that's pretty basic, as well as possibly the implications for people who do identify as multiracial and how these kinds of surveys might impact people's identity, racial identity.

WATERS: Yeah. I had been doing research on ethnic identity and racial identity for a long time and I started out actually, in graduate school. My dissertation, which became the book Ethnic Options was really about trying to put together the Census question on ancestry, where people could give more than one answer, and how people thought about that. So I've always been interested in this question, you know, 'What does it mean to be both Irish and Italian?' And then it expanded afterwards, my research, to think about 'What does it mean to have a black ancestry as Jamaican?' And 'What does it mean to be of mixed racial ancestry?'

And because I had done this research on the Census question, I have, you know, worked with people at the Census Bureau, basically since I first got out of graduate school. I've gone to many meetings and I've been on the PAA Census Advisory Board, and I've gone to conferences about how the Census should ask the questions. And how they might change the questions to better capture what people identify with. And it's been fascinating because the people at the Census Bureau are really terrific researchers, very smart, have, you know, do really high-quality research, but they operate in this constraint of being-doing something that's very political. And so, there's this tension between how they see themselves as social scientists trying to measure a very messy concept-race or ethnicity. And then, the kind of meddling, or, you know, pressure from both interest groups who want their numbers to be high, and Senators and Congressmen who have strong beliefs about 'you shouldn't ask this question' or 'you should ask it this particular way.' So the Census race question, for instance, has many, many categories for Asian groups. So it says, 'Are you white, black,' and then it says 'Are you Filipino, Chinese, Guamanian, and a whole long list of categories. Now, no social scientist would design a question that way that has one level of specificity for one group and another level for another group. But there was a Senator who wanted those Asian categories on and at the last minute he exerted his power and got the question changed. And ever since then, the question has just 
added categories instead of subtracting them. So it's been really interesting to see how, you know, in a democracy, and there definitely is this idea that the Census belongs to the people and there should be all this political input. And yet, then, people complain that the question doesn't make sense and it's not measuring things properly. So, for instance, the separate question for Hispanics, and for race, so you can't tell the Census on the race question that you are Latino or Hispanic; it's a separate question. And that is something that causes all kinds of problems for the Census Bureau because Latino people look at the race question, they don't see the category that reflects them, they check 'other,' and they write it in. That costs a lot of money for the Census Bureau to actually process because they have to actually, you know, have the machine read it and reassign them to another category. And so they would love to change that. But the tests that they've done show that the number of Latinos in the United States would go down if they did that. So there is a lot of pressure from Latino groups themselves to have a separate question because nobody wants their numbers to go down. So it's been fascinating and it's been fun to be a part of it. I've enjoyed it.

ALVORD: Kind of tying together the race/identity question and the Katrina question, what have sociologists, or what have social scientists learned in particular about race through Katrina?

WATERS: Well there's been some survey research asking blacks and whites in the US whether the response to Katrina by the government, both federal and local, was so bad because the majority of the people who were worse off in Katrina were African American. So they've asked a question, 'Do you think that the government response was not as quick and efficient as it could have been because of race?' And whites saying 'no,' it was just, you know, a failure of government, and blacks, overwhelmingly say, 'oh yes, it was because of racism towards the people who experienced this.' So in one way it still shows you that you have very different perspectives on the same phenomenon across blacks and whites in the US.

There's also the ways in which Katrina, for a very short period of time, but very intensely, showed the intense poverty in New 
Orleans. So the people who were on the screens every night when this was on television unfolding in front of Americans' eyes were poor African-Americans. And a lot of people in the United States - some black, but mostly white- had very little knowledge that there were people that were that poor, living in those poor conditions, in our country. And, you know, you would hope that that would have led to more discussion about poverty and about the racial disparities in poverty. And it did a little bit but then the next thing came on $\mathrm{CNN}$ and people lost their interest in it. And it faded from view.

ALVORD: I just wonder like, what are the implications then of that for democracy? In a way, so you mentioned how, you know, whites saw it as a failure of government, blacks saw it as another manifestation of oppression and racism. And so how has that - and you touched on it a little bit yesterday-how has that influenced or impacted civic participation, post-Katrina?

WATERS: Among our respondents, we asked about whether the experience of the hurricane and what happened to New Orleans made them want to get more involved in politics or less, and made them more or less likely to vote? And they said it made them more cynical than they were before and less likely to be politically active. Because it became clear-clearer-to them that government didn't really care too much about people like them. So that was kind of discouraging. Completely understandable, but also discouraging because if you are thinking about how you might make changes, you would hope that, you know, civic participation would rise after something like this, where people would say, 'This shouldn't happen again. Let's organize to have better government.' But in a way, the take-home that a lot of the people had was, 'You can't rely on government,' and also, 'Government doesn't care about people like me.' So it doesn't-you know, 'I should invest my energy elsewhere.'

MCCANNON: You know, that's interesting. It makes me think of, sometimes, I guess, sociologists kind of assume that-well in this particular case we can go all the way back to Marx-and well, you are living in $\mathrm{X}$ condition. A rational person should be expected to 
react in a certain way. You're oppressed, working-class, it is expected that you should want to rise up and be politically active or whatever. So it seems-I know sometimes we kind of go into, at least those of us, graduate students, young scholars, just still learning, that see this, 'Oh, okay, wow, I can see there is a huge problem here. Health care-why aren't more people rallying to do something about it?' And it sort of taps into that a little bit. These assumptions that we kind of approach and think that because people are living in $\mathrm{X}$ condition that we expect them to react in $\mathrm{Y}$ and when they don't, how do we handle that?

WATERS: Yeah. You know I think that's a reason why we need to do research-both surveys and also ethnographies and in-depth interviews with people - to understand how they understand the particular situation that they're in and how different options either come on the table for them or don't. So why a person would conclude from a particular situation that, you know, they should concentrate on themselves and their own families or they should band together with other people. But you know, the other point that I made in the talk yesterday about the research is that the whole response to Katrina has been very individualized and atomized. And so, individuals apply for money to fix up their houses, and they, individuals are either homeowners or renters and they make a kind of cost-benefit analysis about whether or not they're going to go back and fix up their house and go back to their neighborhood. But what they really are craving is the same group of neighbors and extended family and community that they had before the hurricane. And yet there's no mechanism to have collective action about going back. There are in neighborhoods with a little bit more resources than the neighborhoods that our respondents lived in. So in some of the more middle-class neighborhoods, like Lakeview, people were organized, they were on the internet, they were pressuring the government, to have the whole neighborhood come back. But for a lot of our people who were renters or who were homeowners but did not have insurance because these houses had been paid off and they had belonged to their grandmother or greatgrandmother, so they had no need for mortgage insurance. So they didn't have insurance on their houses. 
They are very much making individual decisions about whether to come back and feeling very atomized. So it's not surprising to me that people who were kind of left on their own that way would also just respond that government really is not-or collective action is not the way to change their lives but also mainly just to focus on themselves and their immediate family.

ALVORD: You were mentioning how you wanted to sort of continue this Katrina research, and even looking at the children of the mothers that you interviewed. You have a long history of looking at second-generation immigrants. And I wonder, sort of a two-part question: What's the sociological benefit of looking at [the] second-generation, and what kind of similarities or differences are you expecting to find?

WATERS: Well, I think there's a lot of really interesting and exciting interdisciplinary work being done now on poverty and the biological impacts of poverty. So the effects of stress growing up in neighborhoods on children's ability to learn, on the effects of growing up in stressful environments, on people's not only kind of cognitive abilities but also their behavioral attributes and how much they can adapt to new circumstances and regulate their behavior, et cetera. So I think that this is research that's really looking at kind of the biological imprint of social disadvantage. And so, I actually think that looking at the children of Katrina and following them over time when we have such a rich database on their moms and also on the neighborhoods that they've ended up in, that the study can really look at the longitudinal impact of a disaster which can have, I think, repercussions for the next generation. But also, it can look at kind of changes in poverty levels, and the kinds of neighborhoods people live in, and the effect on children. So, it's not just a disaster study at this point, but it is also kind of a longitudinal study of social changes for these mothers and their children and poverty and moving in or out of poor neighborhoods. So, that's one of the other reasons we want to follow children, is to see how environmental changes impact the kids over time. 
ALVORD: So, what kind of, besides the Katrina [project], what kind of other research projects do you have sort of lined up?

WATERS: Well, I have one other project that is in the field right now. Which is looking at immigrants - Latino immigrants - in Boston, Los Angeles, and Miami, and looking at how they access social services. So it includes both documented and undocumented immigrants and the question is - in Europe, how immigrants get integrated into the society is studied very similarly to how we study it in the US-but in Europe there is a lot of attention to how much of the welfare state immigrants access. But in the US, we really haven't done very much research on that - at all. And that's partly because we have such an attenuated welfare state. But we do actually have programs that immigrants or their children are eligible for-such as food stamps, social welfare benefits, health care, benefits for like early intervention or other kinds of learning assistance for kids. And so we had some questions about both for people who are here legally and for people who are here without documents. How do they learn about where they can get help? How are they treated when they go in to talk to government bureaucrats? How do they get steered to either a church food pantry or to food stamps? And also, how much information do they give to one another about how to navigate this whole system? So we started doing in-depth interviews, and it's very much an ongoing project, but we started in Boston, and we're looking at Dominicans, El Salvadorans, and people from South America, and other places in Central America-Guatemalans. And we found really big differences across the groups, about how much they knew about government programs, and how they learned about how to access them. So we also then did some interviews in Los Angeles and in Miami, and we're finding really interesting things. So that is an exciting project that we're just really gearing up for.

MCCANNON: Nice, that is interesting. I spent a little bit of time in Sweden last year, and the difference in what is provided, the access that new immigrants have to navigating the welfare state is a lot different there than it is here. So, I could see definitely a lot of potential with that type of project, doing comparative- 
WATERS: Right.

MCCANNON: - cross country comparative-type work, even at a qualitative level like that. And talking to people in different countries in these similar situations to kind of get an idea of just how really different it can be. Especially within the United States, just state-to-state-

WATERS: That's right.

MCCANNON: - dealing with different social policy regimes within states, that's definitely very interesting.

WATERS: One interesting thing we found is that in Los Angeles, Mexican immigrants, especially people who have papers, so legal Mexican immigrants, actually go down to Mexico for a lot of their health care because it's cheaper. And in Boston, you're not close enough to make the trip, but... for instance, if you get a dental problem in Los Angeles, it's way cheaper to just drive to Mexico and go to a Mexican dentist to get your teeth taken care of. Whereas in Boston, there really is no place, you just suffer with dental pain or lose your tooth. And of course this goes against all of the ideas that are out there about immigrants coming to the US, to take our health care and our welfare, right? Actually, we're finding the opposite, which is that the immigrants are like, going to someplace where it's much cheaper and they can get care that they need. So yeah, it's an interesting topic and it definitely varies by the region of the country.

ALVORD: Well, Professor Mary Waters, thank you so much. We really appreciate it.

WATERS: Oh, thank you, thank you. It was very fun. 